\title{
ANALISIS HUBUNGAN INDEKS BIAS DAN INTENSITAS CAHAYA PADA BERBAGAI FLUIDA
}

\author{
${ }^{1)}$ M. Akbar Mukhlis, ${ }^{1)}$ Albertus Djoko Lesmono , ${ }^{1)}$ Lailatul Nuraini \\ ${ }^{1)}$ Program Studi pendidikan Fisika FKIP Universitas Jember \\ Email: m.akbarmukhlis@gmail.com
}

\begin{abstract}
This research aimed to examine the relationship between refractive index and light intensity in various fluids. This type of this research was experimental research. The measurement data obtained the refractive index values of various fluids, namely the refractive index of spirit, watered, alcohol, oil, and oil respectively $1.3066 \pm 0.0053,1.319 \pm 0.0056,1.3422 \pm 0.0061,1.438 \pm$ $0.0054,1.576 \pm 0.0068$. The data from the measurement of light intensity in various fluids obtained the valued of the intensity of light that passed through spirit, watered, alcohol, oil, and oil, respectively, namely 1220. $8 \pm 3.72$ lux, $1219 \pm 3.9$ lux, 1216. $2 \pm 3,77$ lux, 1202. $6 \pm 3.88$ lux, and 1180. $2 \pm 4.07$ lux. The results of this research obtained a valued of $r=1$ which indicates that the relationship between the refractive index and light intensity was very strong. The conclusion in this studied was that there was a relationship between refractive index and light intensity. This relationship could been seen in the refractive index, the greater the valued in the fluid would made the transmitted light intensity decrease or inversely proportional.
\end{abstract}

Key word: fluid, light intensity, refractive index

\section{PENDAHULUAN}

Fisika merupakan kajian bidang studi yang mempelajari tentang fenomenafenomena alam yang berkaitan tentang konsep, teori, hukum dan sebagainya (Bektiarso, 2000:11). Pembelajaran fisika pada implementasinya menggunakan proses dan produk dalam penalarannya. Berdasarkan konsep-konsep fisika yang dipelajari satu sama lain memiliki keterkaitan yang dapat saling mempengaruhi. Salah satu contohnya adalah indeks bias dan intensitas cahaya.

Salah satu contoh gelombang elektromagnetik adalah gelombang cahaya. Cahaya memancarkan suatu energi, sebagian dari cahaya tersebut akan diubah menjadi cahaya tampak (visible light). Gelombang cahaya tampak memiliki panjang gelombang berkisar 340 nanometer hingga 700 nanometer yang nantinya cahaya tersebut akan diuraikan dalam beberapa warna (Pamungkas, dkk. 2015: 121).

Indeks bias merupakan salah satu sifat optis dari suatu medium. Perbandingan antara indeks bias diantara dua medium adalah indeks bias relatif. indeks bias mempunyai banyak peran penting dalam bebeapa bidang diantaranya bidang kimia, pengaruh indeks bias dapat digunakan sebagai pengukuran konssntrasi suatu larutan (Sholehah, 2017: 9). Dalam bidang industri indeks bias dapat digunakan untuk pengukuran parameter fisik seperti suhu, 
konsentrasi, tekanan, dan lain-lain (Zamroni, 2013: 108).

Indeks bias merupakan perbandingan kecepatan cahaya pada ruang hampa udara dengan kecepatan cahaya pada suatu medium (Faradilah dan Hendri, 2019: 140). Pada hukum Snelius menjelaskan proses pembiasan terjadi disaat suatu gelombang masuk ke dalam medium yang memiliki indeks bias lebih kecil maka arah rambat gelombangnya akan menjauhi garis normal dan sebaliknya (Abdullah, 2017:610).

Nilai indeks bias cahaya pada tiap fluida berbeda-beda. Semakin besar kerapatan optiknya pada fluida tersebut maka semakin besar nilai indeks biasnya. Cahaya yang memasuki fluida tersebut akan terpecah menjadi cahaya yang dipantulkan dan cahaya yang diteruskan (pembiasan cahaya). Tiap cahaya yang dipantulkan dan dibiaskan pada jenis fluida yang bermacammacam memiliki intensitas cahaya yang berbeda. Intensitas cahaya merupakan daya dari sumber cahaya yang dipancarkan pada sudut tertentu (Zelviana, 2018: 204-205). Intesitas cahaya sering digunakan dalam bidang fotometri atau melihat cahaya dengan panjang gelombang tertentu. Sumber cahaya yang memasuki suatu jenis fluida tertentu akan dipantulkan (refleksi) dan dibiaskan (transmisi).

Semakin terang suatu cahaya maka semakin tinggi pula kepadatan cahaya tersebut. kontras cahaya yang terlalu besar bisa saja menimbulkan distribusi cahaya yang tidak merata. Hal tersebut diakibatkan oleh mata yang tidak melihat langsung cahaya yang berasal dari sumber cahaya, tetapi mata melihat cahaya yang dipantulkan oleh objek tersebut ke mata. (Gunandhi, 2002: 50). Intensitas cahaya yang disebabkan oleh pemantulan dan pembiasan memiliki nilai transimisi dan refleksi. Perbandingan intensitas cahaya setelah mengenai bahan dan sebelum menyentuh bahan dapat ditunjukkan melalui persamaan berikut:

$$
\begin{aligned}
& \mathrm{R}=\frac{\mathrm{I}_{1}}{\mathrm{I}_{0}} \\
& \mathrm{~T}=\frac{\mathrm{I}_{1}}{\mathrm{I}_{0}}
\end{aligned}
$$

$\mathrm{R}$ merupakan nilai Reflektansi, $\mathrm{T}$ adalah Transmitansi, $\mathrm{I}_{0}$ adalah intensitas cahaya sebelum memasuki fluida dan $\mathrm{I}_{1}$ adalah intensitas cahaya setelah memasuki fluida.

Apabila gelombang cahaya yang datang tegak lurus dengan bidang batas dan $\theta_{1}=\theta_{2}=0^{\circ}$ maka akan berlaku persamaan sebagai berikut:

$$
\begin{gathered}
\mathrm{R}=\frac{\mathrm{n}_{2}-\mathrm{n}_{1}}{\mathrm{n}_{1}+\mathrm{n}_{2}} \\
\mathrm{~T}=\frac{2 \mathrm{n}_{1}}{\mathrm{n}_{1}+\mathrm{n}_{2}}
\end{gathered}
$$

\section{METODE}

Jenis penelitian yang digunakan adalah penelitian eksperimen. Penelitian ini dilaksanakan di Laboratorium Fisika Dasar Universitas Jember. Penelitian yang dilakukan adalah menganalisis hubungan indeks bias dan intensitas cahaya pada berbagai macam fluida. Pada penelitian terdapat beberapa variabel yang mempengaruhi penelitian diantaranya variabel bebas, kontrol, dan terikat. Variabel bebas dalam penelitian adalah jenis fluida dan indeks bias berbagai fluida. Variabel kontrol pada penelitian adalah warna cahaya laser (merah), jarak sumber cahaya dengan medium $(5 \mathrm{~cm})$, wadah untuk berbagai fluida, dan sudut yang sama $\left(0^{\circ}\right)$. Variabel terikat pada penelitian ini adalah intensitas cahaya yang diteruskan pada berbagai fluida.

Alur yang digunakan dalam penelitian ini meliputi persiapan, pengumpulan data, analisis data, dan penarikan kesimpulan. Pada tahap persiapan peneliti menyiapkan segala alat dan bahan yang digunakan dalam 
pengukuran. Selanjutnya tahap pengumpulan data, peneliti melaksanakan pengukuran di dalam laboratorium untuk mengumpulkan data-data yang digunakan. Lalu tahap analisis data, pada tahap ini peneliti menganalisis data yang telah terkumpul mengelompokkan data tersebut dalam bentuk tabel dan grafik. Lalu tahap penarikan kesimpulan, pada tahap berikut peneliti mengambil kesimpuln berdasarkan data pada tabel. Adapun tabel yang digunakan sebagai berikut:

Pada tabel tersebut fluida yang digunakan adalah air, alkohol, spirtus, minyak, dan oli. Pada $\mathrm{n}_{1}$ menunjukkan niai indeks bias udara atau medium pertama. Pada $\mathrm{n}_{2}$ indeks bias berbagai jenis fluida yang digunakan. Pada $\mathrm{I}_{0}$ merupakan intensitas cahaya sebelum memasuki fluida, $\mathrm{I}_{1}$ merupakan intensitas cahaya yang memasuki fluida dan terukur pada luxmeter dan $\mathrm{I}_{1}$ ' adalah intensitas cahaya setelah memasuki fluida dengan perhitungan matematis. Data yang telah dianalisis tersebut lalu akan digambarkan pada suatu grafik hasil penelitian.

\section{HASIL DAN PEMBAHASAN}

Laboratorium fisika dasar FKIP, Universitas Jember. Data yang dikumpulkan dalam tabel penelitian berupa nilai indeks bias cahaya pada medium pertama (udara) dan indeks bias pada masing-masing fluida atau pada medium kedua, intensitas cahaya sebelum dan setelah memasuki fluida, dan nilai intensitas cahaya pada masing-masing fluida dengan perhitungan matematis.

Fluida-fluida yang digunakan adalah air, alkohol 97\%, spirtus, minyak goreng, dan oli SAE 20. Hasil dari setiap pengukuran sebagaimana ditunjukkan pada Tabel 1 sampai pada Tabel 5 berikut.
Tabel 1. Air

\begin{tabular}{cccccc}
\hline Fluida & $\mathbf{n}_{\mathbf{1}}$ & $\mathbf{n}_{\mathbf{2}}$ & $\mathbf{I}_{\mathbf{0}}$ & $\mathbf{I}_{\mathbf{1}}$ & $\mathbf{I}_{\mathbf{1}} \mathbf{}^{\prime}$ \\
\hline Air & 1 & 1,3 & 1254 & 1233 & 1090,435 \\
\hline Air & 1 & 1,315 & 1244 & 1221 & 1074,73 \\
\hline Air & 1 & 1,32 & 1241 & 1217 & 1069,828 \\
\hline Air & 1 & 1,328 & 1238 & 1213 & 1063,574 \\
\hline Air & 1 & 1,332 & 1236 & 1211 & 1060,034 \\
\hline
\end{tabular}

Tabel 2. Spirtus

\begin{tabular}{cccccc}
\hline Fluida & $\mathbf{n}_{\mathbf{1}}$ & $\mathbf{n}_{\mathbf{2}}$ & $\mathbf{I}_{\mathbf{0}}$ & $\mathbf{I}_{\mathbf{1}}$ & $\mathbf{I}_{\mathbf{1}}{ }^{\mathbf{1}}$ \\
\hline Spirtus & 1 & 1,29 & 1254 & 1234 & 1095,197 \\
\hline Spirtus & 1 & 1,3 & 1244 & 1223 & 1081,739 \\
\hline Spirtus & 1 & 1,308 & 1241 & 1219 & 1075,39 \\
\hline Spirtus & 1 & 1,315 & 1238 & 1215 & 1069,546 \\
\hline Spirtus & 1 & 1,32 & 1236 & 1213 & 1065,517 \\
\hline
\end{tabular}

Tabel 3. Alkohol

\begin{tabular}{cccccc}
\hline Fluida & $\mathbf{n}_{\mathbf{1}}$ & $\mathbf{n}_{\mathbf{2}}$ & $\mathbf{I}_{\mathbf{0}}$ & $\mathbf{I}_{\mathbf{1}}$ & $\mathbf{I}_{\mathbf{1}}{ }^{\prime}$ \\
\hline Alkohol & 1 & 1,325 & 1254 & 1229 & 1078,71 \\
\hline Alkohol & 1 & 1,334 & 1244 & 1219 & 1065,981 \\
\hline Alkohol & 1 & 1,342 & 1241 & 1215 & 1059,778 \\
\hline Alkohol & 1 & 1,35 & 1238 & 1211 & 1053,617 \\
\hline Alkohol & 1 & 1,36 & 1236 & 1207 & 1047,458 \\
\hline
\end{tabular}

Tabel 4. Minyak

\begin{tabular}{cccccc}
\hline Fluida & $\mathbf{n}_{\mathbf{1}}$ & $\mathbf{n}_{\mathbf{2}}$ & $\mathbf{I}_{\mathbf{0}}$ & $\mathbf{I}_{\mathbf{1}}$ & $\mathbf{I}_{\mathbf{1}}$ \\
\hline Minyak & 1 & 1,42 & 1254 & 1216 & 1036,364 \\
\hline Minyak & 1 & 1,433 & 1244 & 1205 & 1022,606 \\
\hline Minyak & 1 & 1,44 & 1241 & 1201 & 1017,213 \\
\hline Minyak & 1 & 1,447 & 1238 & 1197 & 1011,851 \\
\hline Minyak & 1 & 1,45 & 1236 & 1194 & 1008,98 \\
\hline
\end{tabular}

Tabel 5. Oli

\begin{tabular}{|c|c|c|c|c|c|}
\hline $\begin{array}{c}\text { Flui } \\
\text { da }\end{array}$ & $\mathbf{n}_{1}$ & $\mathbf{n}_{2}$ & $\mathbf{I}_{\mathbf{0}}$ & $\mathbf{I}_{1}$ & $\mathbf{I}_{1}$, \\
\hline Oli & 1 & 1,56 & 1254 & 1194 & 979,6875 \\
\hline Oli & 1 & 1,568 & 1244 & 1183 & 968,8474 \\
\hline Oli & 1 & 1,573 & 1241 & 1179 & 964,6327 \\
\hline Oli & 1 & 1,58 & 1238 & 1175 & 959,6899 \\
\hline Oli & 1 & 1,6 & 1236 & 1170 & 950,7692 \\
\hline
\end{tabular}

yakni Tabel 1 sampai Tabel 5 dapat dijelaskan bahwa pada setiap fluida memiliki nilai indeks bias yang berbeda. Perbedaan nilai indeks bias tersebut sebanding dengan nilai perubahan intensitas cahaya yang dipantulkan. Data nilai indeks 
bias didapatkan dengan melakukan percobaan sederhana hukum Snellius.

Pada data nilai intensitas cahaya didapatkan dengan menggunakan alat bantu berupa luxmeter untuk mendapatkan intensitas cahaya awal $\left(\mathrm{I}_{0}\right)$ dan intensitas cahaya yang dipantulkan $\left(\mathrm{I}_{1}\right)$. Setelah mendapatkan data tersebut nilai intensitas cahaya yang terbaca pada luxmeter akan dibandingkan dengan nilai intensitas cahaya dari perhitungan matematis.

Masing-masing tabel hasil penelitian tersebut juga disajikan dalam bentuk grafik hubungan antara indeks bias fluida $\left(\mathrm{n}_{2}\right)$ dengan intensitas cahaya yang melewati fluida $\left(\mathrm{I}_{1}\right)$ sebagaimana yang dapat ditunjukkan dalam Gambar 1 sampai Gambar 5 berikut ini.

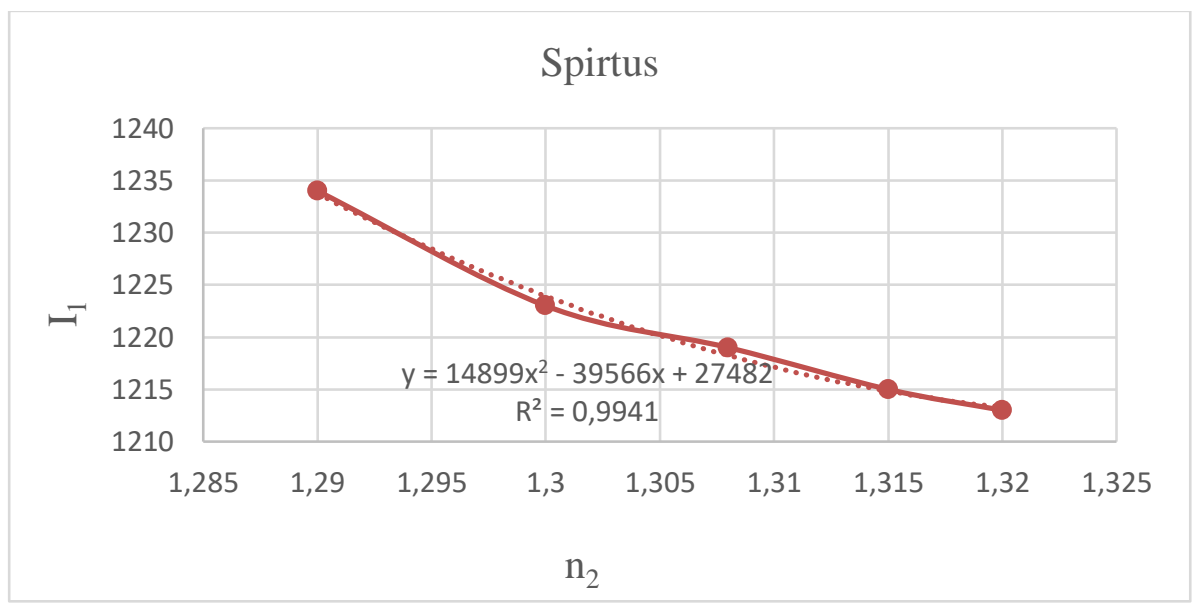

Gambar 1. Grafik pada fluida Spirtus

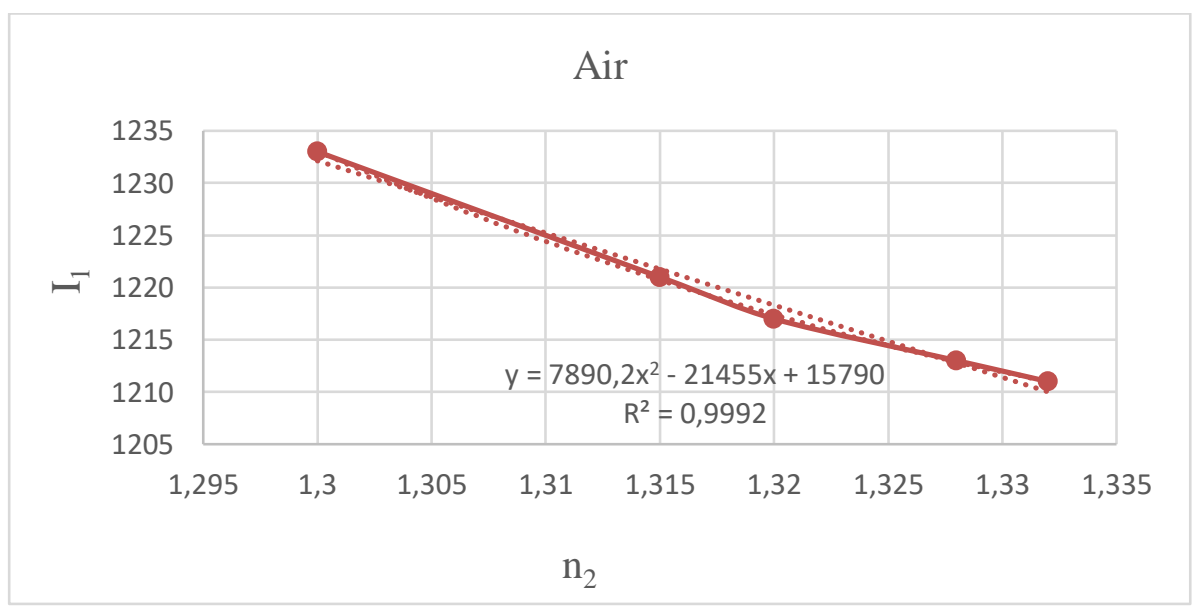

Gambar 2. Grafik pada fluida air 


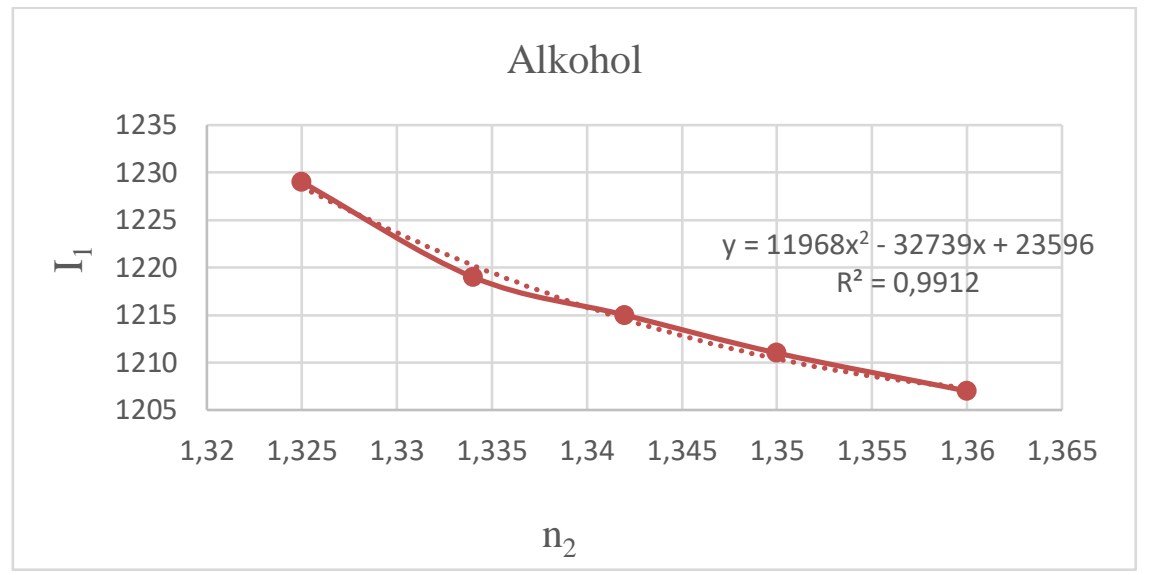

Gambar 3. Grafik pada fluida alkohol

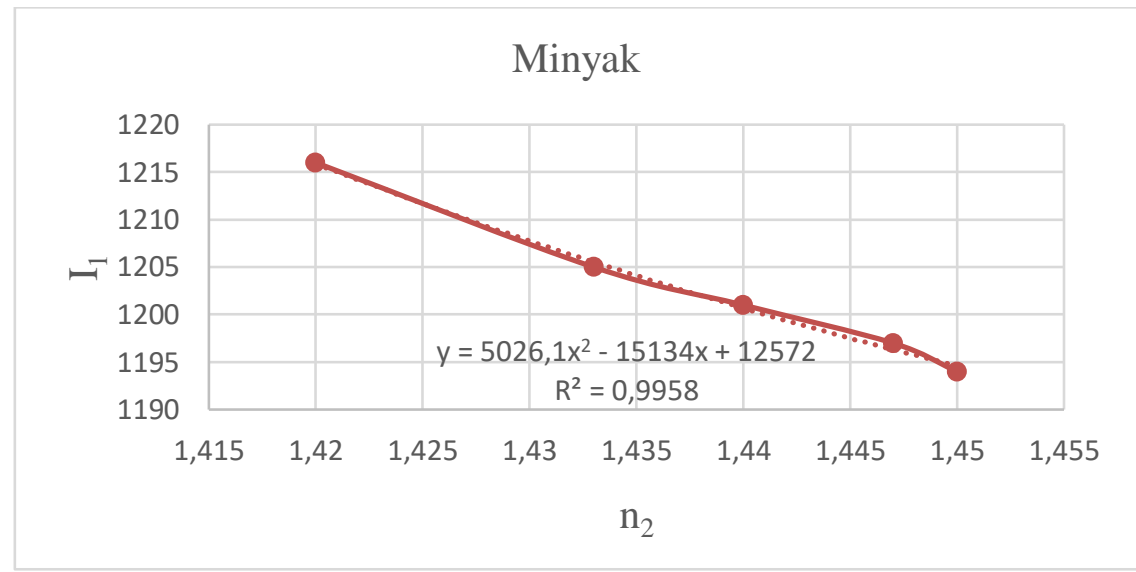

Gambar 4. Grafik pada fluida minyak

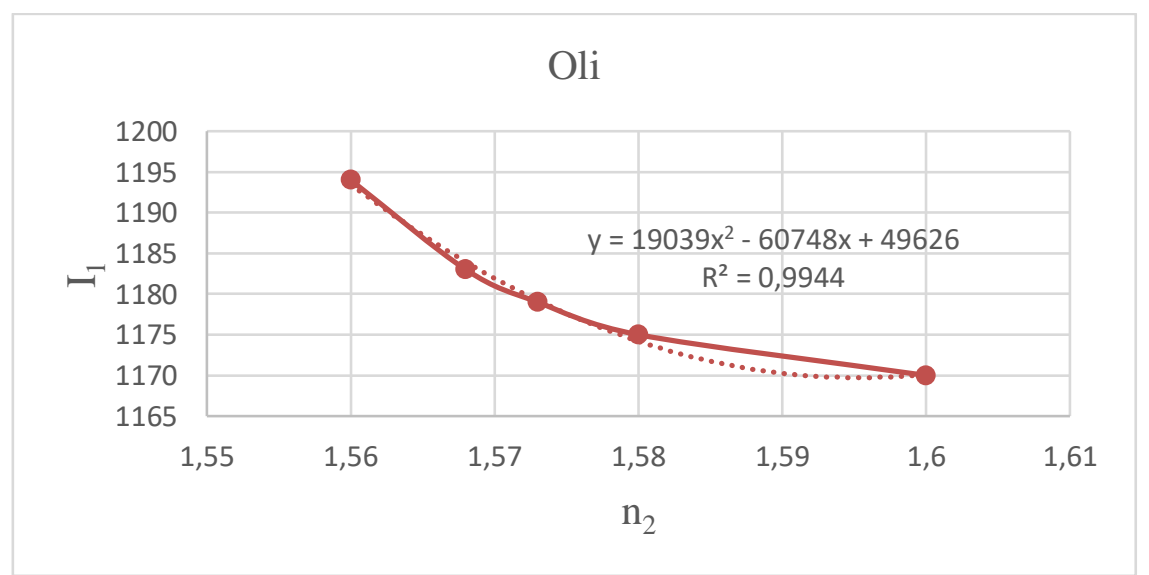

Gambar 5. Grafik pada fluida oli

Berdasarkan data dari tabel dan grafik, peneliti mengkaji hubungan indeks bias zat cair dan intensitas cahaya dari berbagai fluida. Berdasarkan hasil yang 
telah didapatkan maka dapat ditinjau fluida dengan urutan indeks bias terkecil sampai terbesar mengalami penurunan nilai intensitas cahaya yang diteruskan atau ditransmisikan. Penurunan nilai intensitas cahaya tersebut diakibatkan oleh semakin besar nilai indeks bias suatu zat cair maka semakin besar pula kerapatan optik dari zat cair tersebut. Kerapatan optik yang besar akan membuat cahaya yang masuk ke dalam fluida akan dibelokkan lebih besar nilainya. Hal ini dipengaruhi oleh beberapa faktor yang menyebabkan besarnya indeks bias pada jenis fluida yang berbeda bisa bervariasi. Indeks bias zat cair begantung pada kekentalan zat cair itu sendiri (Elisa \& Juliana, 2015). Kerapatan medium mempengaruhi besarnya indeks bias medium tersebut (Hadiyanto dkk., 2010). Panjang gelombang cahaya yang melewati bahan akan mempengaruhi besarnya indeks bias bahan tersebut (Abdullah, 2017). Pada saat pengukuran intensitas cahaya, sumber cahaya yang digunakan adalah sinar laser berwarna merah.

\section{SIMPULAN DAN SARAN}

Berdasakan data yang diperoleh pada hasil dan pembahasan penelitian yang telah diuraikan, maka dapat diambil kesimpulan yaitu: adanya hubungan indeks bias dan intensitas cahaya. Hubungan tersebut terlihat pada indeks bias yang semakin besar nilainya pada fluida akan membuat intensitas cahaya yang ditransmisikan semakin berkurang atau berbanding terbalik.

Adapun saran yang dapat diberikan antara lain bagi guru dapat dijadikan rujukan bahan ajar yang kontekstual dan bagi peneiti lain dapat dijadikan sebagai acuan untuk mengembangkan penelitian ini ke tahap lebih lanjut.

\section{DAFTAR PUSTAKA}

Abdullah, M. (2017). Fisika Dasar 2. Bandung: ITB

Bektiarso.2000. Pentingnya konsepsi awal dalam pembelajaran fisika. Jurnal Saintifika. 1(1): 11-20.

Elisa, dan Juliana. (2015). Perbedaan indeks bias minyak goreng curah dengan minyak goreng kemasan bermerek sunco. Jurnal Fisika Edukasi. 2(2): 76-80.

Faradillah \& Hendri, S. (2019). Mengukur indeks bias berbagai jenis kaca dengan menggunakan prinsip pembiasan. Ijis Edu, 1(2), 140.

Gunandhi, A. (2002). Perancangan dan implementasi alat ukur cahaya sederhana. Jurnal Teknik Elektro. 12(1): 50-58.

Hadiyanto, E., A. Rofiq, dan H. Sugito. (2010). Aplikasi portable brix meter untuk pengukuran indeks bias. Jurnal Fisika Berkala. 13(4): 113-118.

Pamungkas, M., Hafiddudin, dan Y. S. Rohmah. (2015). Perancang dan realisasi alat pengukur intensitas cahaya. Jurnal ELKOMIKA. 2(3): $120-132$.

Sholehah, I. (2017). Pengaruh variasi jarak tempuh kendaraan terhadap indeks bias oli dengan menggunakan metode difraksi fraunhofer. Skripsi. Jember. Fakultas matematika dan ilmu pengetahuan alam universitas jember.

Zamroni, A. (2013). Pengukuran indeks bias zat cair melalui metode pembiasan menggunakan plan paralel. Jurnal IPA. 3(2): 108111.

Zelviana, S. (2018). Pengaruh ketebalan bahan penghalang terhadap intensitas radiasi relatif. Jurnal Teknosains. 12(2): 203-209. 